\title{
Calcium/calmodulin-dependent kinase IV contributes to translation-dependent early synaptic potentiation in the anterior cingulate cortex of adult mice
}

Hiroki Toyoda ${ }^{1,4}$, Ming-Gao Zhao ${ }^{1,5}$, Valentina Mercaldo ${ }^{1}$, Tao Chen ${ }^{1}$, Giannina Descalzi ${ }^{1}$, Satoshi Kida ${ }^{3}$, Min Zhuo ${ }^{1,2^{*}}$

\begin{abstract}
Calcium/calmodulin-dependent kinase IV (CaMKIV) phosphorylates the major transcription factor, cyclic AMPresponsive element binding protein (CREB), which plays key roles in synaptic plasticity and memory consolidation. Our previous study showed that long-term potentiation (LTP) in the anterior cingulate cortex (ACC) was significantly enhanced in transgenic mice overexpressing CaMKIV. Considering that the CaMKIV-CREB pathway plays a central role in the protein synthesis-dependent LTP, it is possible that upregulation of CaMKIV contributes to enhancement of LTP by promoting protein synthesis. To test this possibility, we examined the effects of transcription and translation inhibitors on synaptic potentiation induced by pairing of synaptic activity with postsynaptic depolarization (paired training) in ACC pyramidal neurons of wild-type and CaMKIV transgenic mice. We found that synaptic potentiation induced by paired training was partially inhibited by transcription or translation inhibitors both in wild-type and CaMKIV transgenic mice; the extent of inhibition was markedly larger in the CaMKIV transgenic mice than in the wild-type mice. Biochemical and immunohistochemical studies revealed that CaMKIV was distributed in the membrane, cytosol and nucleus of ACC neurons. Our results reveal in the first time a transcription- and translation-dependent component of early synaptic LTP in adult ACC synapses, and demonstrate that CaMKIV enhances early synaptic potentiation by activating new protein synthesis.
\end{abstract}

\section{Introduction}

The long-lasting changes of neural circuitry in forebrain structures including the anterior cingulate cortex (ACC) are believed to contribute to emotion, learning, memory and pain [1-6], and such long-term changes in neural circuitry may require new protein synthesis. Long-term potentiation (LTP) is typically divided into early-phase and late-phase LTP, in which the latter is mainly thought to be dependent on protein synthesis. At the CA1 [7] and CA3 [8] synapses, protein synthesis inhibitors disrupt late-phase but not early-phase LTP. By contrast, other studies reported that early-phase LTP in CA1 [9], CA3 [10], and dentate gyrus [11] was suppressed by protein

\footnotetext{
* Correspondence: min.zhuo@utoronto.ca

'Department of Physiology, Faculty of Medicine, University of Toronto,

Toronto, Ontario, Canada

Full list of author information is available at the end of the article
}

synthesis inhibitors (see Table 1). Thus, it is likely that protein synthesis-dependent mechanisms play critical roles in not only late-phase but also early-phase LTP, at least in part. However, little is known about whether transcription and translation affects early-phase LTP within ACC synapses.

It has been well established that the cyclic AMPresponsive element binding protein (CREB) is a major transcription factor associated with long-term memory $[12,13]$, and calcium-calmodulin-dependent protein kinase IV (CaMKIV) plays an essential role in activitydependent CREB phosphorylation [14-16]. In the hippocampus, the CaMKIV-CREB pathway is required for protein synthesis-dependent late-phase LTP $[17,18]$. On the other hand, it is conceivable that CaMKIV is also involved in early-phase LTP, because our previous study has shown that early-phase LTP in the ACC, amygdala, 
Table 1 Effects of protein synthesis inhibitors on earlyphase LTP (E-LTP) and late-phase LTP (L-LTP)

\begin{tabular}{cccc}
\hline Brain region & E-LTP & L-LTP & References \\
\hline CA1 & Blocked & & {$[9]$} \\
& Blocked & & {$[28]$} \\
& No effect & blocked & {$[54]$} \\
& No effect & blocked & {$[8]$} \\
& No effect & blocked & {$[22]$} \\
& No effect & blocked & {$[55]$} \\
& Partially blocked & blocked & {$[29]$} \\
CA3 & No effect & blocked & {$[56]$} \\
& Blocked & & {$[30]$} \\
Dentate gyrus & Partially blocked & & {$[10]$} \\
& No effect & blocked & {$[57]$} \\
Spinal cord & Partially blocked & blocked & {$[11]$} \\
Amygdala & No effect & blocked & {$[58]$} \\
Prefrontal cortex & No effect & blocked & {$[59]$} \\
ACC & No effect & blocked & {$[60]$} \\
& Partially blocked & & This study \\
\hline
\end{tabular}

insular cortex and somatosensory cortex was disrupted in CaMKIV knockout mice [19]. Additionally, we previously reported that early-phase LTP in ACC neurons of CaMKIV transgenic mice was significantly enhanced compared with those of wild-type mice [20]. Thus, it is possible that CaMKIV modulates early-phase LTP by regulating transcription and translation in ACC synapses. In our behavioral study, trace fear memory was significantly enhanced in CaMKIV transgenic mice, suggesting that CaMKIV affects the ability to sustain attention in a manner needed for retaining of the memory [20], although its mechanism remains unknown. Revealing how CaMKIV contributes to transcription and translation dependent-synaptic plasticity in ACC synapses will be helpful to understand ACC-related functions such as trace fear memory.

In the present study, we employed integrative approaches to investigate if the enhancement of early LTP by CaMKIV is dependent on transcription and translation. Here, we show that synaptic potentiation induced by paired training was significantly suppressed by transcription and translation inhibitors both in wildtype and CaMKIV transgenic mice; the extent of suppression of LTP was much larger in CaMKIV transgenic mice than in wild-type mice. Furthermore, biochemical and immunostaining observations revealed that CaMKIV is indeed distributed in the membrane, cytosol and nucleus of ACC neurons. These observations strongly suggest that overexpression of CaMKIV enhances early synaptic potentiation by promoting protein synthesis in ACC neurons.

\section{Results}

Effects of a transcription inhibitor on synaptic potentiation in ACC neurons

We have previously shown that synaptic potentiation in ACC neurons from the CaMKIV transgenic mice was significantly enhanced by spike-timing protocol which involves pairing three presynaptic stimuli, which caused three excitatory post-synaptic potentials (EPSPs) (10 ms ahead), with three postsynaptic action potentials at $30 \mathrm{~Hz}$, paired 15 times every $5 \mathrm{~s}$ [20]. In the present study, we induced synaptic potentiation by pairing of synaptic activity with postsynaptic depolarization (or called paired training) (80 pulses of presynaptic stimulation at $2 \mathrm{~Hz}$ in layer $\mathrm{V}$ with postsynaptic depolarization at $+30 \mathrm{mV}$ ) in the wild-type and CaMKIV transgenic mice. This protocol is useful to induce robust LTP in the ACC [4] and amygdala [21]. First, we investigated if actinomycin-D, a transcription inhibitor, affects synaptic potentiation in ACC neurons induced by the paired training. Actinomycin-D was used at a concentration of $40 \mu \mathrm{M}$, a dose that reduces uridine incorpolation into RNA by 77\% [22]. We performed whole-cell patchclamp recordings from visually identified pyramidal neurons in layer II/III of the ACC. Fast excitatory postsynaptic currents (EPSCs) were obtained by delivering focal electrical stimulation to layer V. We identified pyramidal neurons based on the pyramidal shape of their somata by putting Lucifer yellow into the intracellular solution and confirmed that the recordings were performed from cortical pyramidal cells by injecting depolarizing currents into the neuron [4].

The paired training induced a significant, long-lasting potentiation of synaptic responses in the ACC neurons of wild-type mice $(154.4 \pm 10.0 \%, \mathrm{n}=8 / 5$ mice, $P<0.05$ compared with baseline at $25-30$ min postinduction, Fig. 1A and 1C). To investigate whether protein synthesis is involved in such synaptic potentiation, we tested the effect of a transcription inhibitor, actinomycin-D. In the ACC slices pretreated with $40 \mu \mathrm{M}$ actinomycin-D for $30 \mathrm{~min}$, LTP induced by the paired training was significantly suppressed compared with control $(135.7 \pm 9.6 \%, \mathrm{n}=9 / 5$ mice, $P<0.05$ compared with baseline at 25-30 min post-induction, Fig. $1 \mathrm{~A}$ and $1 C)$. Analysis of the time course of the effects of actinomycin-D on LTP in wild-type mice revealed that actinomycin-D significantly suppressed the synaptic potentiation at 15-20 and 25-30 min after LTP introduction $(P<0.05$ compared with baseline, Fig. 1C), although there was no significant reduction at 0-5 $\mathrm{min}$ after introduction (Fig. 1C). This result suggests that paired training itself can drive protein synthesis by activating transcription at $15 \mathrm{~min}$ after LTP introduction in ACC neurons of wild-type mice. 

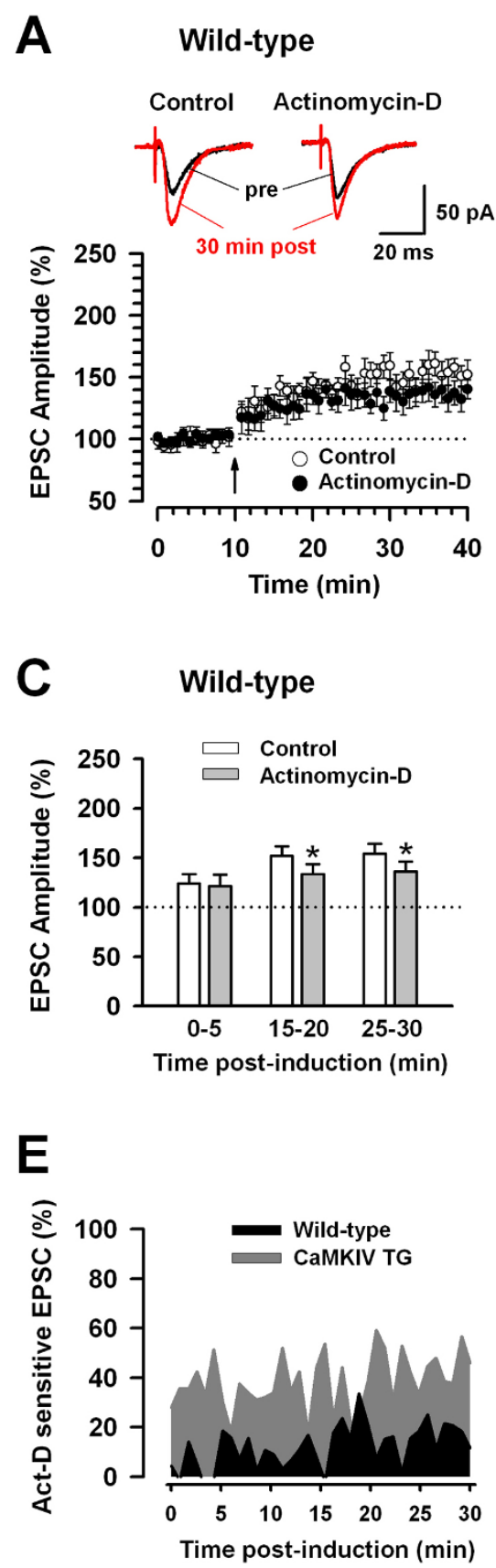
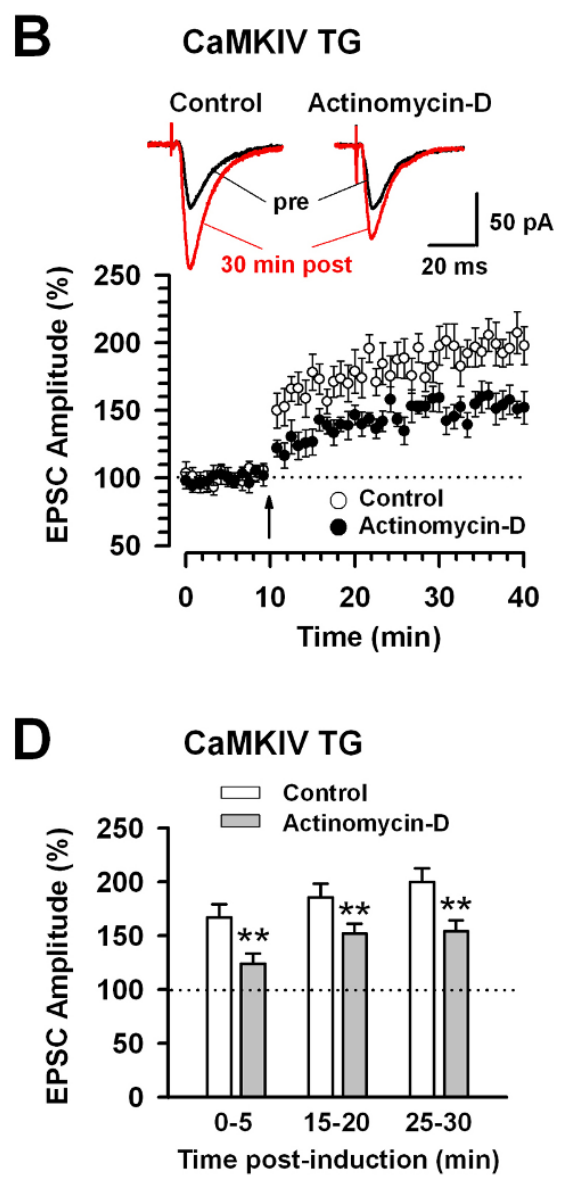

$\mathbf{F}$

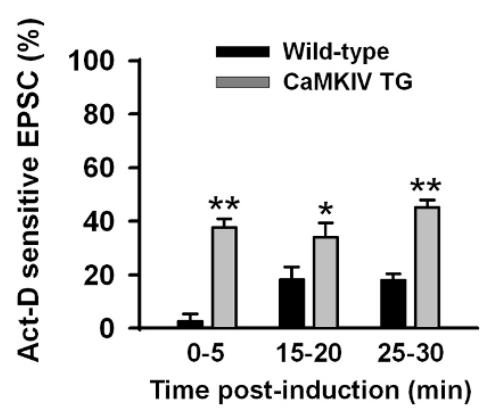

Figure 1 Enhanced synaptic potentiation in ACC neurons of CaMKIV transgenic mice mediated by transcription activity. A: The paired training inducing LTP in ACC neurons of wild-type mice $(n=8 / 5$ mice). Partial inhibition of LTP by $40 \mu M$ actinomycin-D in ACC neurons of wild-type mice ( $n=9 / 5$ mice). B: Enhanced LTP in ACC neurons of CaMKIV transgenic (TG) mice ( $n=8 / 5$ mice). Marked inhibition of LTP by actinomycin-D in ACC neurons of CaMKIV TG mice ( $n=7 / 5$ mice). A-B: The insets showing averages of five EPSCs at baseline responses (pre) and at 25-30 min (30 min post) after the paired training (arrow); the dashed lines indicating the mean basal synaptic responses. C: Statistical results showing the significant inhibition of LTP by actinomycin-D at 15-20 and 25-30 min after induction of LTP in ACC neurons of wild-type mice. The dashed line indicating the mean basal synaptic responses. ${ }^{*} P<0.05$ compared to control. D: Statistical results showing the significant inhibition of LTP by actinomycin-D at 0-5, 15-20 and 25-30 min after induction of LTP in ACC neurons of CaMKIV TG mice. The dashed line indicating the mean basal synaptic responses. ${ }^{*} P<0.01$ compared to control. E: Actinomycin-D (Act-D) sensitive synaptic potentiation in ACC neurons of CaMKIV TG mice is larger than that of wild-type mice. F: Statistical results showing that Act-D sensitive synaptic potentiation in ACC neurons of CaMKIV TG mice is significantly larger than that of wild-type mice at 0-5, 15-20 and 25-30 min after induction of LTP. ${ }^{*} P<0.05$, **P 0.01 compared to wild-type mice. 
In the CaMKIV transgenic mice, synaptic potentiation was significantly enhanced in comparison to the wildtype mice $(199.7 \pm 13.2 \%$ of baseline at $25-30$ min postinduction, $\mathrm{n}=8 / 5$ mice, Fig. $1 \mathrm{~B}$ and $1 \mathrm{D}, P<0.05 \mathrm{com}-$ pared with wild-type mice, see Fig. 1A and 1C), similar to the results obtained in our previous study [20]. When LTP was induced in the ACC slices of CaMKIV transgenic mice pretreated with actinomycin-D, the synaptic potentiation was remarkably suppressed (152.6 $\pm 9.7 \%$ of baseline at 25-30 min post-induction, $\mathrm{n}=7 / 5 \mathrm{mice}$, $P<0.01$ compared with control, Fig. 1B and 1D). The analysis of the time course of the effects of actinomycinD on LTP in the CaMKIV transgenic mice revealed that actinomycin-D significantly suppressed the synaptic potentiation at 0-5, 15-20 and 25-30 min after LTP introduction $(P<0.01$ compared with baseline, Fig. 1D). This result suggests that, as in wild-type mice, paired training itself can induce protein synthesis by activating transcription immediately after LTP introduction in ACC neurons of CaMKIV transgenic mice. By calculating the actinomycin-D sensitive synaptic potentiation in wild-type and CaMKIV transgenic mice, the effects of transcription on the synaptic potentiation caused by the paired training was compared between the two groups (Fig. 1E). The actinomycin-D sensitive synaptic potentiation in the ACC neurons of CaMKIV mice was significantly larger than that of wild-type mice at 0-5, 15-20 and 25-30 min after LTP introduction $(P<0.01$ at 0 5 min post-induction, $P<0.05$ at $15-20$ min post-induction, $P<0.01$ at $25-30$ min post-induction, Fig. $1 \mathrm{~F}$ ). These results indicate that gene transcription was markedly enhanced in the ACC neurons of CaMKIV transgenic mice compared to those of wild-type mice.

\section{Effects of a translation inhibitor on synaptic potentiation in ACC neurons}

Next, we investigated the effects of a translation inhibitor, anisomycin, on synaptic potentiation in ACC neurons induced by paired training. Anisomycin was used at a concentration of $20 \mu \mathrm{M}$, which inhibited the maintenance phase of hippocampal LTP $[8,23]$. In the ACC slices pretreated with $20 \mu \mathrm{M}$ anisomycin, LTP induced by the paired training was significantly reduced in comparison with control $(133.0 \pm 10.5 \%, \mathrm{n}=8 / 5$ mice, $P<$ 0.05 compared with baseline at $25-30 \mathrm{~min}$ post-induction, Fig. 2A and 2C). Analysis of the time course of this effect in wild-type mice revealed that anisomycin significantly suppressed synaptic potentiation at 15-20 and 25-30 min but not at 0-5 min after LTP introduction $(P<0.05$ compared with baseline, Fig. $2 C)$, similar to the results obtained in the presence of actinomycin-D (Fig. 1C). This result also suggests that paired training itself can drive protein synthesis by activating translation at 15 min after LTP introduction in ACC neurons of wild-type mice.

In the CaMKIV transgenic mice, synaptic potentiation was also significantly reduced by anisomycin in comparison with control $(151.6 \pm 9.8 \%$ of baseline at $25-30 \mathrm{~min}$ post-induction, $\mathrm{n}=6 / 4$ mice, $P<0.05$ compared with control; Fig. 2B and 2D). Analysis of the time course of this effect in CaMKIV transgenic mice revealed that anisomycin significantly suppressed synaptic potentiation at 0-5, 15-20 and 25-30 min after LTP introduction $(P<0.01$ compared with baseline, Fig. 2D). This result also suggests that paired training can induce protein synthesis by activating translation immediately after LTP introduction in the ACC neurons of CaMKIV transgenic mice. By calculating the anisomycin sensitive synaptic potentiation in wild-type and CaMKIV transgenic mice, the effects of translation on synaptic potentiation caused by the paired training was compared between these two groups of mice (Fig. 2E). The anisomycin sensitive synaptic potentiation in the ACC neurons of the CaMKIV mice was significantly larger than that of the wild-type mice at 0-5, 15-20 and 25-30 min after introduction of LTP $(P<0.01$ compared with baseline, Fig. 2F). These results indicate that not only gene transcription but also gene translation were markedly enhanced in the ACC neurons of CaMKIV transgenic mice compared to those of wild-type mice.

\section{Effects on AMPA and NMDA receptor mediated responses} in ACC neurons

To exclude the possible inhibition of basal synaptic transmission by translation and transcription inhibitors, we measured the $\alpha$-amino-3-hydroxy-5-methyl-4-isoxazole-propionate (AMPA) or N-methyl-D-aspartic acid (NMDA) receptor-mediated basal EPSCs. In particular, the NMDA receptor is essential for the induction of LTP in forebrain areas including the ACC $[4,24-26]$. First, we investigated the effects of $40 \mu \mathrm{M}$ actinomycinD on AMPA receptor-mediated EPSCs. Actinomycin-D had almost no effect on the AMPA receptor-mediated EPSCs in the wild-type ( $\mathrm{n}=8 / 4$ mice) and CaMKIV transgenic mice ( $\mathrm{n}=7 / 4$ mice) (Fig. $3 \mathrm{~A}$ and $3 \mathrm{C}$, respectively). Next, we examined the effects of actinomycin-D on NMDA receptor-mediated EPSCs. Actinomycin-D also had no effect on NMDA receptor-mediated EPSCs in wild-type ( $\mathrm{n}=6 / 3$ mice) and CaMKIV transgenic mice ( $\mathrm{n}=6 / 3$ mice) (Fig. 3B and 3D, respectively).

We further tested the effects of $20 \mu \mathrm{M}$ anisomycin on AMPA receptor-mediated EPSCs. Similar to the effect of actinomycin-D, anisomycin had almost no effect on AMPA receptor-mediated EPSCs in wild-type $(\mathrm{n}=8 / 5$ mice) and CaMKIV transgenic mice ( $\mathrm{n}=8 / 5$ mice) (Fig. 4A and 4C, respectively). We then examined the 

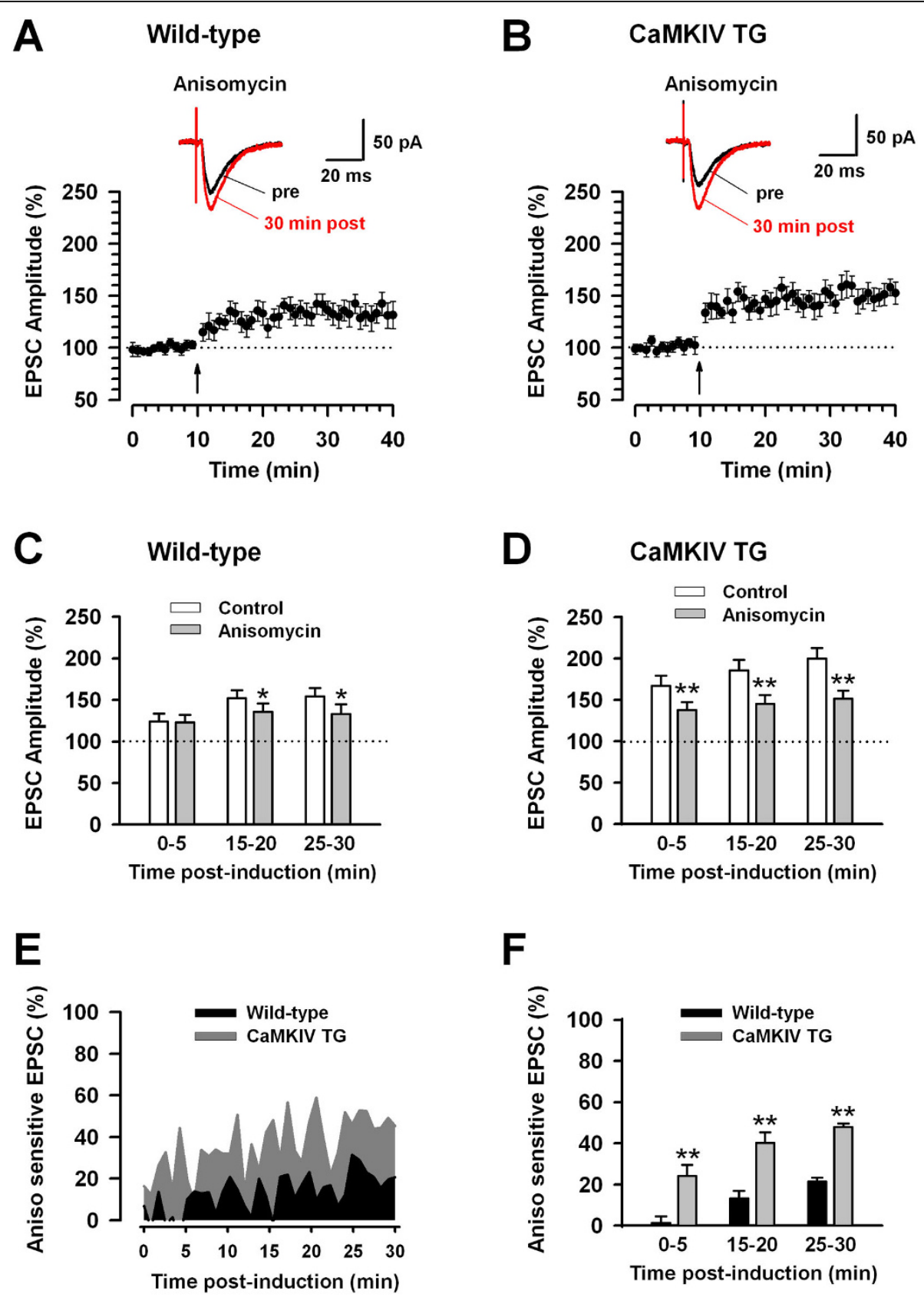

Figure 2 Enhanced synaptic potentiation in the ACC neurons of CaMKIV transgenic mice mediated by translation activity. A: Partial inhibition of LTP by $20 \mu \mathrm{M}$ anisomycin in ACC neurons of wild-type mice $(n=7 / 5$ mice). B: Remarkable inhibition of LTP by actinomycin in ACC neurons of CaMKIV transgenic (TG) mice ( $n=6 / 4$ mice). A-B: The insets showing averages of five EPSCs at baseline responses (pre) and at 25-30 min (30 min post) after the paired training (arrow); the dashed lines indicating the mean basal synaptic responses. C: Statistical results showing the significant inhibition of LTP by anisomycin at 15-20 and 25-30 min after induction of LTP in ACC neurons of wild-type mice. Summary results in control using data in Figure 1C. The dashed line indicating the mean basal synaptic responses. ${ }^{*} P<0.05$ compared to control. D: Statistical results showing the significant inhibition of LTP by anisomycin at 0-5, 15-20 and 25-30 min after induction of LTP in ACC neurons of CaMKIV TG mice. Summary results in control using data in Figure 1D. The dashed line indicating the mean basal synaptic responses. ${ }^{* *} P<0.01$ compared to control. E: Anisomycin (Aniso) sensitive synaptic potentiation in ACC neurons of CaMKIV TG mice is larger than that of wild-type mice. F:

Statistical results showing that Aniso sensitive synaptic potentiation in ACC neurons of CaMKIV TG mice is significantly larger than that of wildtype mice at 0-5, 15-20 and 25-30 min after induction of LTP. ${ }^{* *} P<0.01$ compared to wild-type mice. 


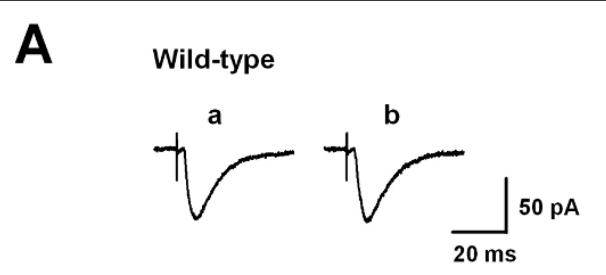

B

Wild-type
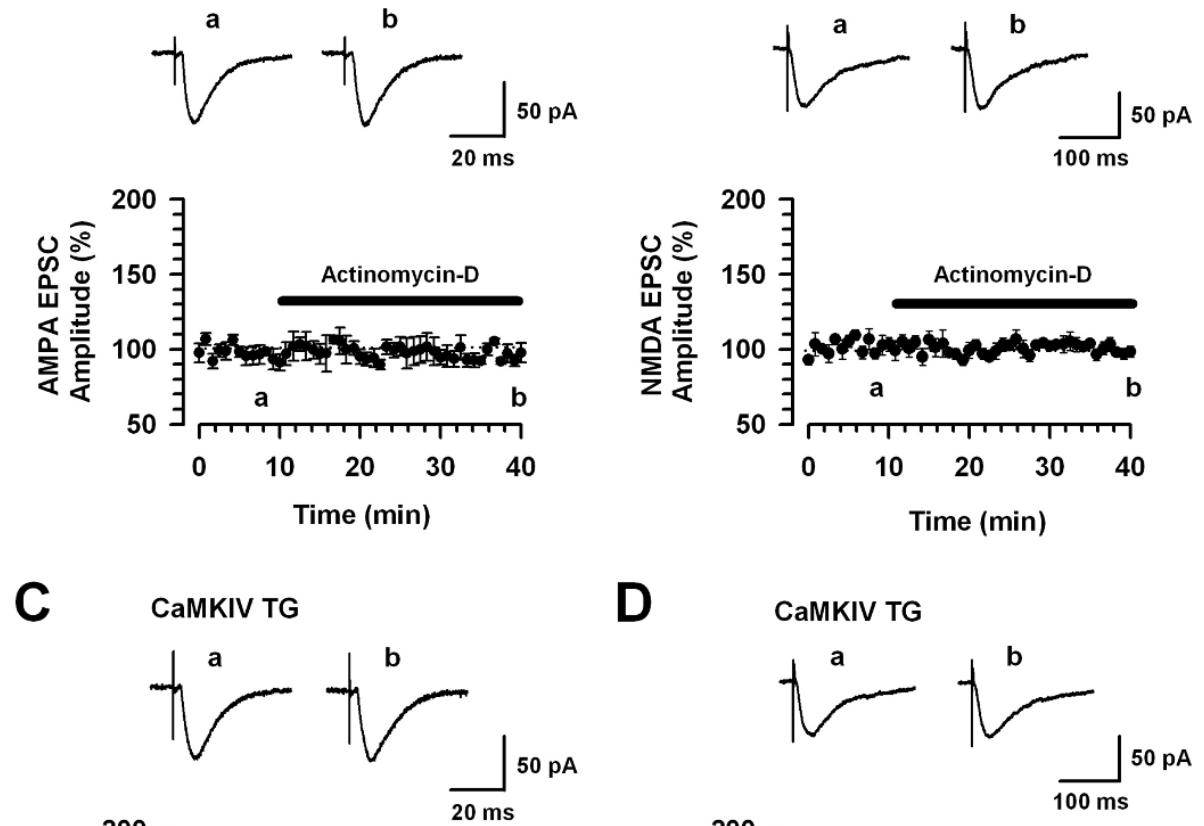

D

\section{CaMKIV TG}
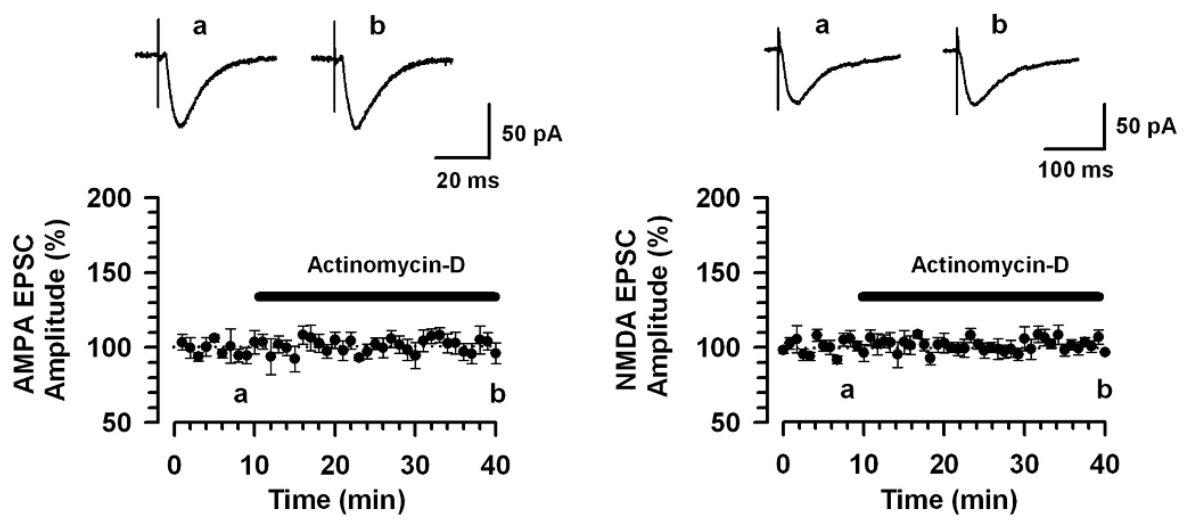

Figure $3 \mathrm{~A}$ transcription inhibitor has no effect on basal synaptic transmission. A: No effect of actinomycin-D (40 $\mu M)$ on AMPA receptormediated EPSCs in ACC neurons of wild-type mice $(n=8 / 4$ mice). B: No effect of actinomycin-D on NMDA receptor-mediated EPSCs in ACC neurons of wild-type mice ( $n=6 / 3$ mice). C: No effect of actinomycin-D on AMPA receptor-mediated EPSCs in ACC neurons of CaMKIV TG mice ( $n=7 / 4$ mice). D: No effect of actinomycin-D on NMDA receptor-mediated EPSCs in ACC neurons of CaMKIV TG mice ( $n=6 / 3$ mice). A-D: The dashed line indicating the mean basal synaptic responses. The insets showing averages of five EPSCs at baseline responses (a) and 25-30 min (b) after application of actinomycin-D (black bar).

effects of anisomycin on NMDA receptor-mediated EPSCs. Anisomycin also showed no effect on NMDA receptor-mediated EPSCs in wild-type $(\mathrm{n}=8 / 5$ mice $)$ and CaMKIV transgenic mice ( $\mathrm{n}=9 / 5$ mice) (Fig. 4B and $4 \mathrm{D}$, respectively). These results suggest that these inhibitors did not cause any functional modifications of AMPA and NMDA receptors.

\section{Expression of CaMKIV in ACC neurons of wild-type and CaMKIV transgenic mice}

We performed immunostaining experiments to examine the expression of CaMKIV in the ACC neurons of wildtype and CaMKIV transgenic mice. We found that a larger number of CaMKIV immunopositive neurons were observed in the CaMKIV transgenic mice than in the wild-type mice in layers II/III and V/VI of ACC
(Fig. 5A-D). We also tested the ratio of CaMKIV immunoreactivity between neuronal nuclei and cytoplasm in brain slices from wild-type and CaMKIV transgenic mice (Fig. 5E). An obvious increased expression of CaMKIV immunoreactivity in the nuclei was observed in CaMKIV transgenic mice (nuclei/cytosolic ratio of CaMKIV staining fluorescence intensity, $0.58 \pm 0.02$ in wild-type and $1.06 \pm 0.03$ in CaMKIV transgenic mice, $P<0.001)$.

\section{Expression of CaMKIV in cytosol and membrane} compartments in the ACC neurons

In the present study, we found that synaptic potentiation caused by paired training was significantly suppressed by transcription and translation inhibitors in wild-type and CaMKIV transgenic mice (Fig. 1). Thus, 


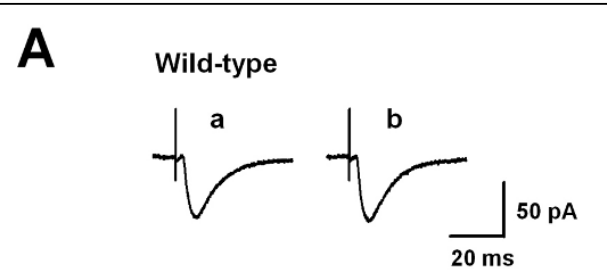

B

Wild-type
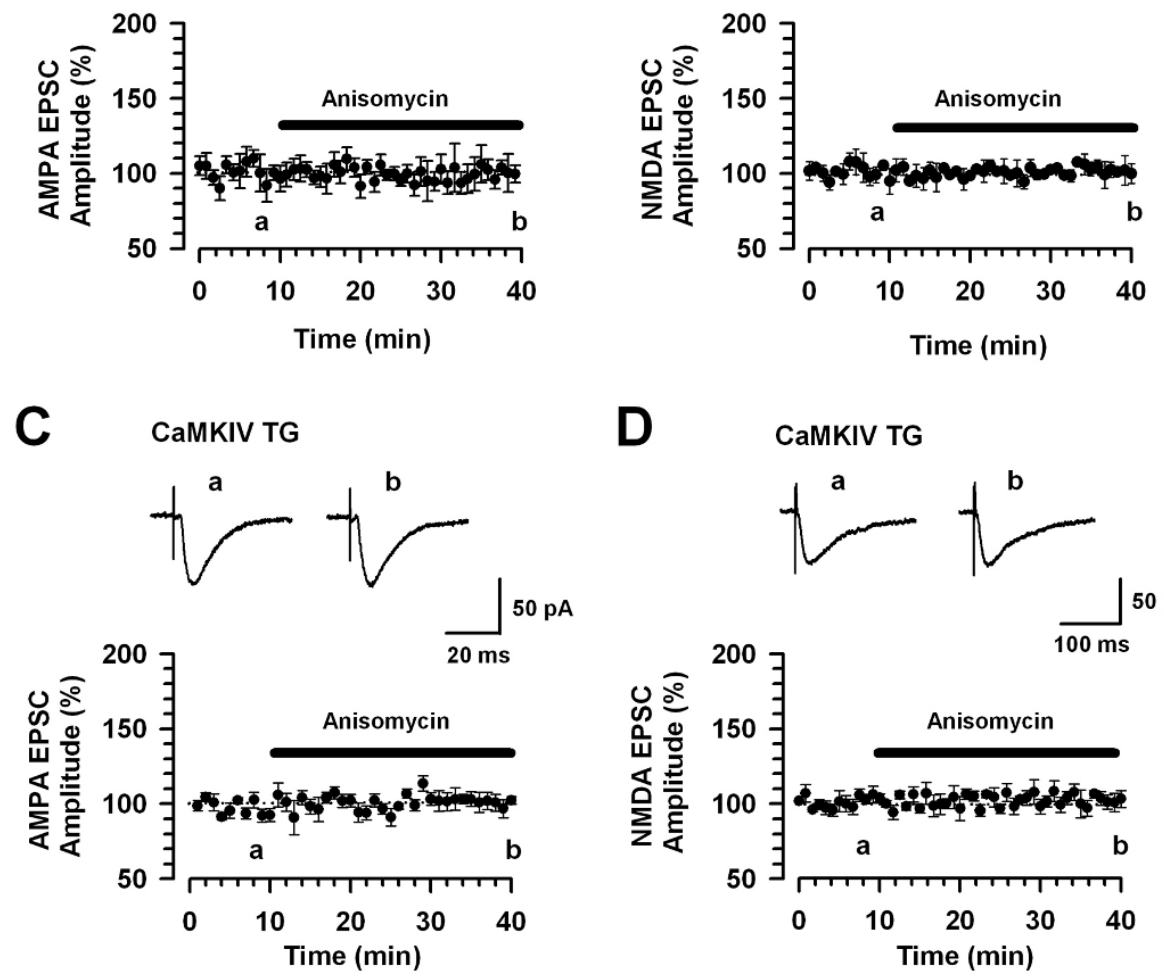

D

\section{CaMKIV TG}
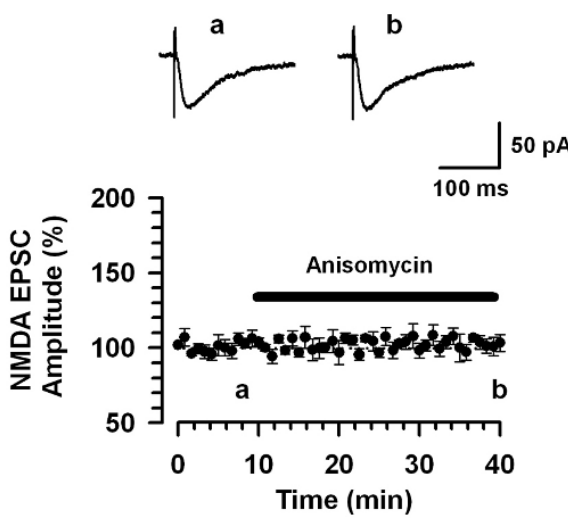

Figure 4 A translation inhibitor has no effect on basal synaptic transmission. A: No effect of anisomycin (20 $\mu M)$ on AMPA receptormediated EPSCs in ACC neurons of wild-type mice ( $n=8 / 5$ mice). B: No effect of anisomycin on NMDA receptor-mediated EPSCs in ACC neurons of wild-type mice ( $n=8 / 5$ mice). C: No effect of anisomycin on AMPA receptor-mediated EPSCs in ACC neurons of CaMKIV transgenic (TG) mice ( $n=8 / 5$ mice). D: No effect of anisomycin on NMDA receptor-mediated EPSCs in ACC neurons of CaMKIV TG mice $(n=9 / 5$ mice). AD: The dashed line indicating the mean basal synaptic responses. The insets showing verages of five EPSCs at baseline responses (a) and 25-30 min (b) after application of anisomycin (black bar).

we next examined the expression of CaMKIV within the cytosol and membrane compartments in the ACC neurons of wild-type mice by Western blot analysis. We observed expression of CaMKIV protein in both cytosol and membrane samples, and found no significant difference in the expression levels (Fig. 6). These results suggest that CaMKIV in membrane compartments may contribute to early synaptic potentiation in ACC neurons.

\section{Discussion}

Activity-dependent activation of CaMKIV is critical for LTP induction in the ACC and is also critical for ACCrelated brain functions such as trace fear memory [20]. Although CaMKIV is highly expressed in the ACC [19], little is known about how CaMKIV-induced protein synthesis contributes to the early-phase of synaptic potentiation in ACC neurons. The present study has demonstrated that synaptic potentiation in CaMKIV transgenic mice was remarkably inhibited by transcription and translation inhibitors in comparison with that in wild-type mice. Our biochemical and immunohistochemical studies revealed that CaMKIV was distributed in the membrane, cytosol and nucleus of ACC neurons. Especially, the nuclear/cytosolic ratio was significantly larger in the CaMKIV transgenic mice than in the wildtype mice, suggesting an enhanced expression of CaMKIV in the nuclei of CaMKIV transgenic mice. These results demonstrate for the first time that CaMKIV enhances short-term synaptic potentiation by activating protein synthesis in ACC neurons. Inhibitors of transcription and translation may inhibit the expression of 


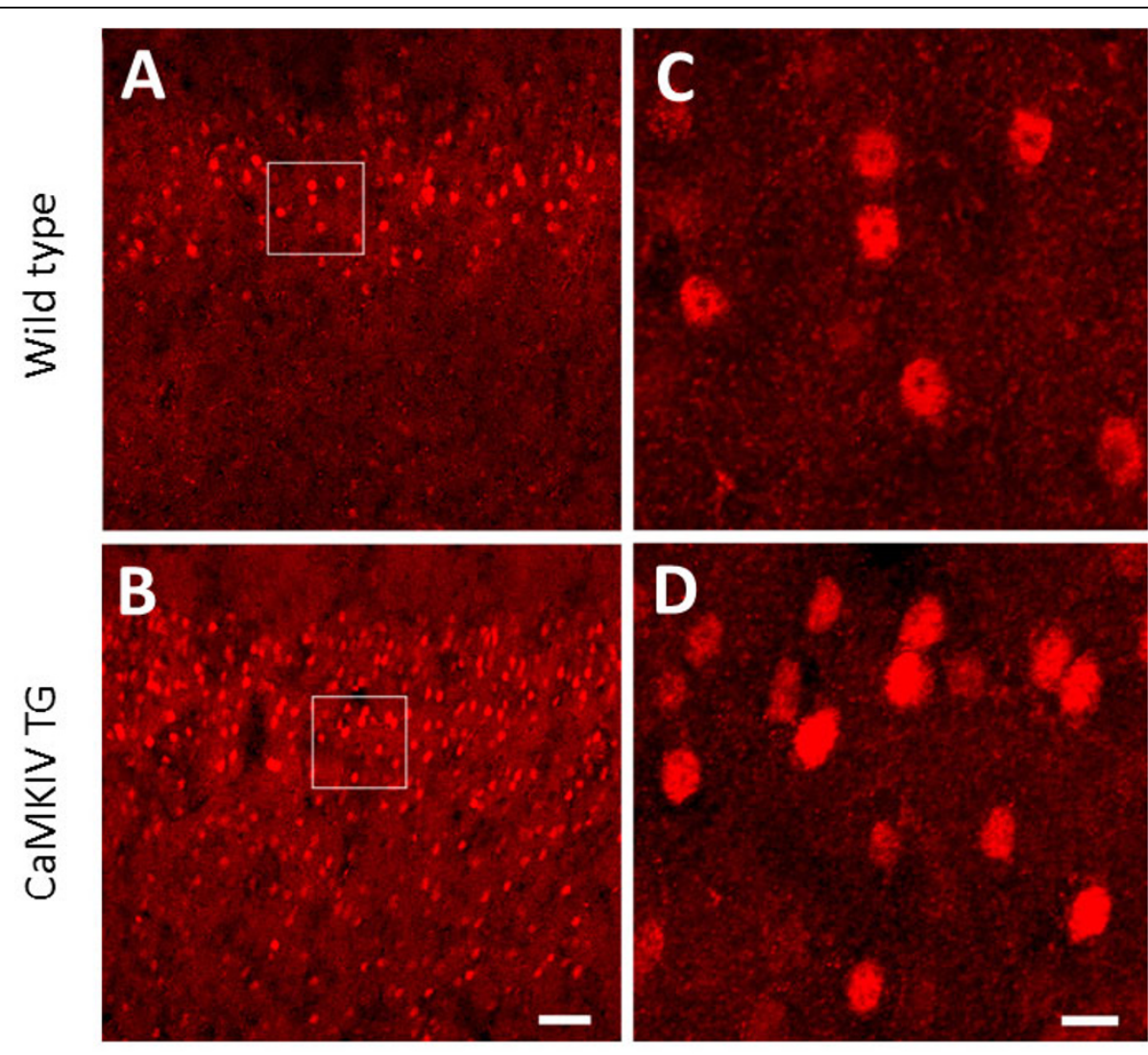

$\mathbf{E}$

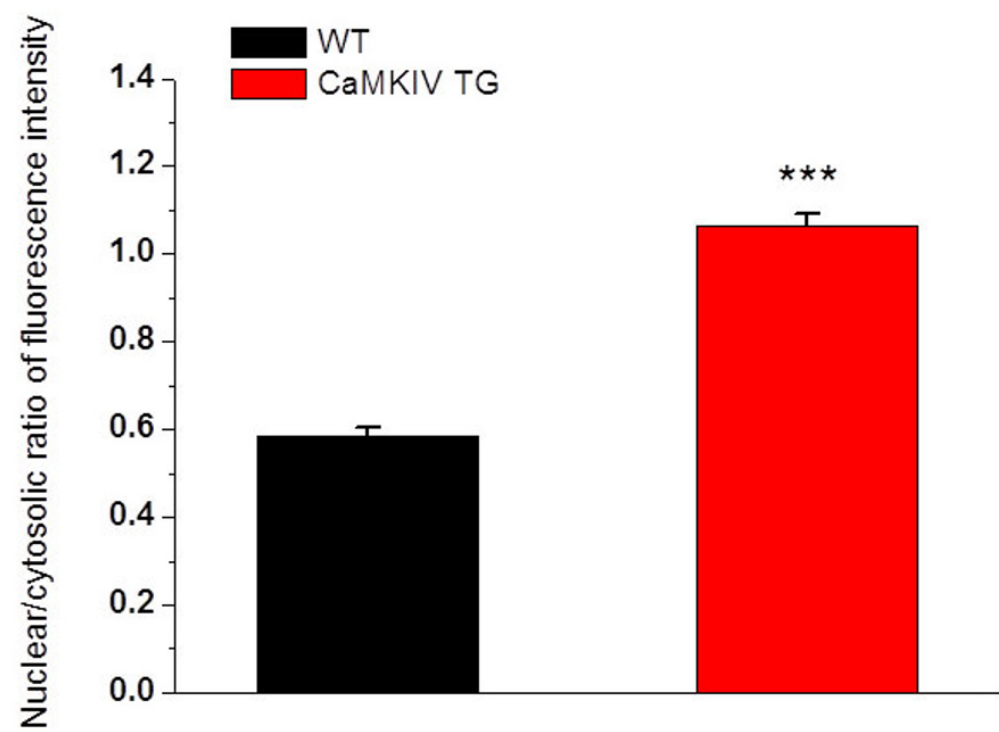

Figure 5 Overexpression of CaMKIV in the ACC neurons of the CaMKIV transgenic mice. A: CaMKIV immunoreactive (IR) neurons are mainly distributed in layer II/III of ACC in the wild-type (WT) mice. B: A larger number of CaMKIV-IR neurons are observed in layers II/II and VNI of ACC in the CaMKIV transgenic (TG) mice. C-D: (C) and (D) showing enlarged images from rectangle areas in (A) and (B), respectively.

Overexpression of CaMKIV immunoreactivity in the nuclei was observed in CaMKIV TG mice. E: Summary data of CaMKIV in ACC from the WT and CaMKIV TG mice. Bars equal to $50 \mu \mathrm{m}$ in (A) and (B) and $10 \mu \mathrm{m}$ in (C) and (D). ${ }^{* *}, P<0.001$. 


\section{Wild- type CaMKIV Expression}
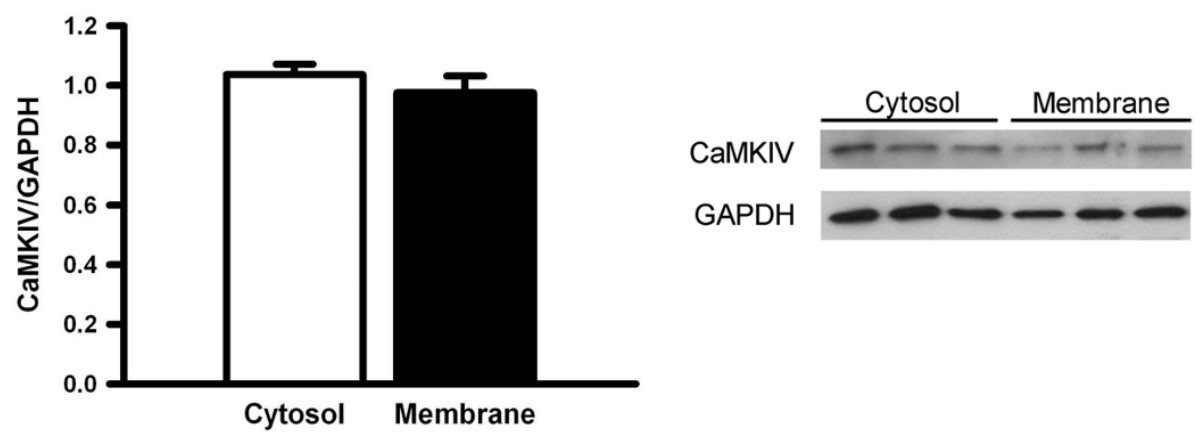

Figure 6 Similar expression levels of CaMKIV in cytosol and membrane compartments of ACC neurons. Western blot analysis showing CaMKIV expression in cytosol and membrane fractions. There is no difference in CaMKIV expression between cytosol and membrane samples.

short-lived proteins required for E-LTP, since these inhibitors were added 30 min before the induction of potentiation.

\section{Role of neuronal activity on protein synthesis-dependent LTP}

LTP is initially achieved by posttranslational modifications of pre- and postsynaptic proteins following the induction of LTP and is later stabilized by transcription and translation $[7,8]$. Thus, LTP is divided into two phases such as early-phase and late-phase LTP; earlyphase LTP depends on the activation of kinases and phosphatases, while late-phase LTP depends on new protein synthesis. Although it is generally believed that early-phase LTP is independent of protein synthesis, the role of protein synthesis in early-phase LTP in ACC neurons was poorly understood. Considering that latephase LTP was disrupted by application of protein synthesis inhibitors before and during LTP induction while their application after LTP induction had no effect on its maintenance [9], the late-phase LTP would be necessary for a transient but not persistent upregulation of protein synthesis. Moreover, strong synaptic stimulation causes gene expression [27]. Thus, it is possible that the LTP induction stimulation itself can drive protein synthesis, thereby affecting the early-phase LTP. In this study, we found that the early synaptic potentiation induced by the paired training in ACC neurons of wildtype mice was significantly suppressed by protein synthesis inhibitors. Furthermore, Western blot and immunostaining analysis revealed that CaMKIV was indeed distributed in the membrane, cytosol and nucleus of ACC neurons. Accordingly, it is likely that the LTP induction stimuli readily recruit CaMKIV in membrane compartments, leading to protein synthesis. Taken together, these results suggest that the early-phase synaptic potentiation caused by the paired training in
ACC neurons was partly mediated by a protein synthesis-dependent mechanism.

Time course for transcription- and translation-related early synaptic potentiation

Although it is considered that early-phase LTP is independent of protein synthesis, a number of studies have demonstrated that early-phase LTP was partially or completely inhibited by protein synthesis inhibitors at CA1 $[9,28,29]$, CA3 $[10,30]$, and dentate gyrus [11] (see Table 1).

Similar to these reports, synaptic potentiation at 15-20 and 25-30 min after LTP induction was significantly suppressed by protein synthesis inhibitors in ACC neurons of wild-type mice, as shown in the present study. Considering that the synaptic potentiation at 0-5 min after LTP induction was not inhibited by protein synthesis inhibitors, protein synthesis-dependent synaptic potentiation begins at 15 min after LTP introduction in ACC neurons. This result indicates that blockade of transcription and translation selectively inhibited the early-phase LTP without affecting LTP induction.

It has been traditionally thought that new protein synthesis are performed in the cell body and transported to the activated synapses. However, numerous studies indicated that LTP induction stimuli induce local protein synthesis in dendritic spines of the postsynaptic neurons $[31,32]$. It is likely that new proteins are synthesized at the activated dendritic spines of ACC neurons. The time course of new protein synthesis in the postsynaptic neurons after LTP induction stimuli has been reported. In CA1 region of the hippocampus, protein kinase $\mathrm{M} \zeta$ appeared $10 \mathrm{~min}$ after LTP induction [33]. In addition, it was also reported that LTP induction led to the increase of $\alpha$ CaMKII protein in the dendrites of stimulated hippocampal CA1 pyramidal neurons within 5 min of LTP induction [34]. Thus, protein synthesis in 
the postsynaptic neurons after LTP induction seems to be rapid, and such time course of protein synthesis is almost consistent with our data presented here. Together, these observations indicate that the mechanisms underlying early-phase LTP involve new protein synthesis.

\section{Role of CaMKIV in synaptic plasticity in ACC neurons}

In the present study, we found that transcription- and translation-dependent synaptic potentiation was markedly enhanced in CaMKIV transgenic mice at 0-5, 15-20 and 25-30 min after induction of LTP. On the other hand, these inhibitors did not cause any effects on AMPA and NMDA receptor-mediated EPSCs in CaMKIV transgenic mice (Fig. 3 and 4), suggesting that the inhibition of synaptic potentiation by protein synthesis inhibitors was not due to a functional modification of AMPA and NMDA receptors. Thus, it is clearly indicated that the downstream targets of these receptors affected the early-phase LTP in ACC neurons of the CaMKIV transgenic mice. Several mechanisms could explain the role of CaMKIV in early-phase protein synthesis dependent LTP. First, synaptic proteins required for synaptic potentiation have been primed by overexpression of CaMKIV. Since our immunohistochemical study revealed that translocation of CaMKIV into the nuclei was markedly larger in the CaMKIV transgenic mice than in the wild-type mice, protein synthesis would be readily caused by LTP induction in the CaMKIV transgenic mice. Second, it has been demonstrated that CaMKIV phosphorylates and regulates the function of synaptic proteins including the actin binding protein synapsin I [35] and the microtubule regulator Stathmin [36]. Thus, the synaptic structural change in ACC neurons caused by CaMKIV may enhance the early-phase of synaptic potentiation.

The ACC is believed to be important in learning, memory and emotion, and pain in the mammalian brain [4,37-44], and LTP in the ACC is a vital key mechanism for cortical synaptic plasticity [6]. Through pharmacological and genetic studies, the molecular and cellular mechanisms of synaptic potentiation in the ACC are beginning to be elucidated $[5,6]$. The enhancement of neuronal activity caused by LTP inducing stimuli (strong tetanic stimulation, theta bust stimulation, paired training and spike-timing protocol) increases the release of the excitatory neurotransmitter glutamate in ACC synapses [5]. Subsequently, NMDA receptors including NR2A and NR2B can be activated, resulting in the elevation of intracellular $\mathrm{Ca}^{2+}$ in postsynaptic cells [4]. The elevation of the intracellular $\mathrm{Ca}^{2+}$ at postsynaptic cells activates a series of intracellular signaling pathways which contribute to LTP in the ACC. It has been well established that $\mathrm{Ca}^{2+}$ binds to calmodulin (CaM), which activates $\mathrm{CaM}$ target proteins, such as $\mathrm{Ca}^{2+} / \mathrm{CaM}$-dependent protein kinases (PKC, CaMKII and CaMKIV), CaM-activated ACs (AC1 and 8), and the CaM-activated phosphatase calcineurin in the hippocampus $[45,46]$. During synaptic potentiation within the ACC, we have reported that activation of $\mathrm{AC} 1$ and CaMKIV is important among the CaM target proteins mentioned above $[19,25]$. As the downstream target of AC1, cyclic-AMP (cAMP)-dependent protein kinase (PKA) is known to activate extracellular signal-regulated kinase (ERK) and ERK/MAPK (mitogen-activated protein kinase). Since ERK, c-Jun N-terminal kinase (JNK) and p38, family members of MAPKs, have been found to be critical in the induction of LTP in the ACC [47], AC1 may activate these MAPKs. Subsequently, the activated ERK/ MAPK likely has multiple targets including CREB that is required for long-term synaptic changes in ACC neurons [19]. Although CaMIV is thought as the late signaling molecule, our observations clearly indicate that CaMKIV contributes to early enhancement of responses by promoting protein synthesis. Therefore, it is possible that CaMKIV is important synaptic plasticity in the ACC.

In summary, we demonstrate strong evidence that CaMKIV enhances synaptic plasticity in ACC neurons by promoting protein synthesis. Elucidating the molecular and cellular mechanisms in synaptic plasticity in the ACC may help us to determine the new insights of cortical plasticity and its related physiological and pathophysiological functions.

\section{Materials and methods \\ Animals}

All adult C57BL/6 mice were purchased from Charles River. Transgenic mice overexpressing CaMKIV were generated as previously described [48]. Briefly, we constructed a transgene that contained a $\alpha$ CaMKII promoter, a hybrid intron in the 5' untranslated leader, the coding region of CaMKIV fused with the Flag tag sequence at the $\mathrm{N}$-terminus and a polyadenylation signal. The CaMKII promoter has been known to exhibit strong activity in regions of the forebrain including the hippocampus, cortex and striatum [49,50]. Among three lines of transgenic mice generated, transgenic line 2 showed the highest levels of transgene expression in the forebrain area [48]. Thus, transgene line 2 was used for the present experiments. Control wildtype mice were littermates of transgenic mice. All mice were maintained on a $12 \mathrm{~h}$ light: dark cycle with food and water provided ad libitum. The Animal Studies Committee at the University of Toronto approved all experimental protocols, which were in accordance with the guidelines of the Canadian Council on Animal Care. 


\section{Slice preparation}

Mice were anesthetized with 1-2\% halothane and decapitated. Coronal brain slices $(300 \mu \mathrm{m})$ containing the ACC from 6-8-week-old C57BL/6 male mice and mice with CaMKIV overexpression were prepared using standard methods $[4,51]$. Slices were transferred to a submerged recovery chamber with oxygenated $\left(95 \% \mathrm{O}_{2}\right.$ and $5 \% \mathrm{CO}_{2}$ ) artificial cerebrospinal fluid (ACSF) containing (in $\mathrm{mM}$ ): $\mathrm{NaCl}, 124 ; \mathrm{KCl}, 2.5 ; \mathrm{CaCl}_{2}, 2 ; \mathrm{MgSO}_{4}$, 2; $\mathrm{NaHCO}_{3}, 25 ; \mathrm{NaH}_{2} \mathrm{PO}_{4}, 1$; glucose, 10; at room temperature for at least $1 \mathrm{~h}$.

\section{Whole-cell patch-clamp recordings}

All electrophysiological experiments were performed at room temperature. An Axioskop 2FS microscope (Zeiss, Germany) with infrared DIC optics was used for visualization of whole-cell patch-clamp recording. Excitatory postsynaptic currents (EPSCs) were recorded from layer II/III neurons with an Axon 200B amplifier (Molecular Devices, CA), and the stimulations were delivered by a bipolar tungsten stimulating electrode placed in layer $\mathrm{V}$ of the ACC slices. EPSCs were induced by repetitive stimulations (duration is $200 \mu \mathrm{s}$, intensity is adjusted to induce EPSCs with an amplitude of 50-100 pA) at 0.02 $\mathrm{Hz}$ and neurons were voltage-clamped at $-70 \mathrm{mV}$. The recording pipettes (3-5 M $\Omega$ ) were filled with solution containing (in mM): $\mathrm{CsMeSO}_{3}, 102$; TEA chloride, 5; $\mathrm{NaCl}$, 3.7; EGTA, 0.2; HEPES, 20; MgATP, 2; NaGTP, 0.3 ; QX-314 chloride, 5 (adjusted to $\mathrm{pH} 7.2$ with $\mathrm{CsOH})$. LTP was induced with paired training within 12 min after establishing the whole-cell configuration to avoid washout of intracellular contents that are critical for the establishment of synaptic plasticity [4]. The induction protocol, referred to as paired training, for LTP involved pairing presynaptic 80 pulses at $2 \mathrm{~Hz}$ with postsynaptic depolarization at $+30 \mathrm{mV}$. The N-methyld-aspartate (NMDA) receptor-mediated component of EPSCs was pharmacologically isolated in ACSF containing 6-cyano-2,3-dihydroxy-7-nitro-quinoxailne acid (CNQX; $25 \mu \mathrm{M})$. Neurons were voltage-clamped at -30 $\mathrm{mV}$ and NMDA receptor-mediated EPSCs were evoked at $0.05 \mathrm{~Hz}$. Picrotoxin $(100 \mu \mathrm{M})$ was always present to block $\gamma$-aminobutyric acid $\mathrm{GABA}_{\mathrm{A}}$ receptor-mediated inhibitory currents and monitored throughout the synaptic currents. Actinomycin-D and anisomycin (Sigma) were dissolved in DMSO, and diluted down to achieve a final concentration of 40 and $20 \mu \mathrm{M}$, respectively (in $0.01 \%$ DMSO). The ACC slices were pretreated with actinomycin-D or anisomycin for $30 \mathrm{~min}$ before LTP induction, which was maintained throughout the recording time. Control experiments using DMSO vehicle had no effects on baseline synaptic responses and LTP in ACC slices. Access resistance was 15-30 M $\Omega$ and was monitored throughout the experiment. Data were discarded if access resistance changed more than $15 \%$ during an experiment. Statistical comparisons were performed using the Student's t-test. Data were expressed as mean \pm S.E.

\section{Immunohistochemistry}

Wild-type and CaMKIV transgenic mice ( $n=3$ in each group) were anesthetized with isoflurane and perfused with $0.1 \mathrm{~mol} / \mathrm{L}$ phosphate buffered saline (PBS, pH 7.27.4) via the ascending aorta followed by $4 \%$ paramaformaldehyde in $0.1 \mathrm{~mol} / \mathrm{L} \mathrm{PB}$. The brains were then removed, and postfixed in the same fixative for $2 \mathrm{~h}$ before cryoprotection in PBS containing 30\% sucrose overnight at $4{ }^{\circ} \mathrm{C}$. Every sixth sections of $25 \mu \mathrm{m}$ thickness, serially cut through the brain in cryostat, were collected. Sections containing ACC were then used for CaMKIV immunoreactivity. Sections were sequentially incubated with the following solutions: (1) a solution of $3 \%$ bovine serum albumin (BSA, Sigma, St. Louis, USA), $0.3 \%$ Triton $\mathrm{X}-100$ containing rabbit antibody against CaMKIV (ab3557; 1:1000, Abcam, USA) for 2 days at $4^{\circ} \mathrm{C}$, (2) Rhodamine-conjugated goat anti-rabbit (1:200, Chemicon) in PBS containing 3\% BSA and $0.3 \%$ Triton $\mathrm{X}-100$ for $24 \mathrm{~h}$ at $4^{\circ} \mathrm{C}$. All sections were rinsed with PBS $(3 \times 10 \mathrm{~min})$ after each step. Sections were then mounted onto clean glass slides, airdried, coverslipped with a mixture of $50 \%(\mathrm{v} / \mathrm{v})$ glycerin and $2.5 \%(\mathrm{w} / \mathrm{v})$ triethylene diamine (anti-fading agent) in 0.01 M PBS, and observed with an laser-scanning confocal microscope (FV1000, Olympus, Japan). No staining was observed on brain sections when the primary antibody was omitted or replaced by normal rabbit serum from the protocol. Images were captured and analyzed with the assistance of Image-Pro Plus 5.0 software (Media Cybernetics, Inc., USA). Measurements of relative fluorescence intensity in the whole nuclear area as compared with that in the cytoplasm were applied [19]. All data was shown as a ratio between the nuclear and cytosolic area of each neuron. Only neurons with sharp boundaries and a well-defined nucleus were considered. Thirty neurons were measured from three different sections, for each animal, and averaged finally.

\section{Western blot analysis}

Membrane preparation was performed as previously described [52] with minor changes. Briefly, ACC samples were dissected in cold D-PBS and resuspended in Buffer 1 (2 mM Tris-EDTA, $320 \mathrm{mM}$ sucrose, $5 \mathrm{mM}$ $\mathrm{MgCl}_{2}$, and $1 \times$ protease inhibitor cocktail, $\mathrm{pH} 7.4$ ), and homogenized. Each sample was centrifuged at 1000xg for $10 \mathrm{~min}$ and the supernatants (S1) were recovered. The remaining pellet (P1) was then resuspended in Buffer $2(50 \mathrm{mM}$ Tris- $\mathrm{HCl}, 2 \mathrm{mM}$ Tris-EDTA, $5 \mathrm{mM}$ $\mathrm{MgCl}_{2}$, and $1 \times$ phosphatase inhibitor cocktail 1 and 2, 
$\mathrm{pH} 7.0$ ) and centrifuged at $1000 \mathrm{xg}$ for $10 \mathrm{~min}$, with its supernatant (S2) collected and combined with S1. The remaining pellet (P2) was resuspended in Buffer 2, and again centrifuged at $1000 \mathrm{xg}$ for $10 \mathrm{~min}$., and its supernatant (S3) was combined with S1 and S2. Combined supernatant fractions (S1, S2 and S3) were finally centrifuged at 39,000xg for $30 \mathrm{~min}$, the resulting supernatant contained the cytosolic fractions, and the resulting pellet (membrane fractions) was resuspended in Buffer 3 (50 mM Tris- $\mathrm{HCl}, 2 \mathrm{mM}$ Tris-EDTA, $3 \mathrm{mM} \mathrm{MgCl}_{2}$, and $1 \times$ phosphatase inhibitor cocktail 1 and 2, $\mathrm{pH}$ 7.4). Western blot was performed as previously described [53]. Sample protein concentrations were quantified using Bradford assay, and electrophoresis of equal amounts of total protein was performed on NuPAGE 4-12\% Bis-Tris Gels (Invitrogen, Carlsbad, CA). Separated proteins were transferred to polyvinylidene fluoride membranes (Pall Corporation, East Hills, NY) at $4^{\circ} \mathrm{C}$ overnight for analysis and were then probed with with primary CaMKIV antibody (1:1000, mouse monoclonal), followed by horseradish peroxidase (HRP)-coupled secondary antibody diluted at 1:3000 for 2 hours followed by enhanced chemiluminescence detection of the proteins with Western lightning chemiluminescence reagent plus (PerkinElmer Life Sciences). ImageJ software (National Institute of Health) was used to assess the density of immunoblots.

\section{List of abbreviations}

ACC: anterior cingulate cortex; ACSF: artificial cerebrospinal fluid; AMPA: $\alpha$-amino-3-hydroxy-5-methyl-4isoxazolepropionic acid; CaMKIV: calcium/calmodulindependent protein kinase IV; CREB: cyclic AMP-responsive element binding protein; EPSC: excitatory postsynaptic current; LTP: long-term potentiation; NMDA: $\mathrm{N}$-methyl D-aspartate receptor.

\section{Acknowledgements \\ This work was supported by grants from the EJLB-CIHR Michael Smith Chair in Neurosciences and Mental Health, CIHR operating grants CIHR81086 and CIHR84256, Canada Research Chair, and NeuroCanada to M.Z. M.Z. is also supported by the World-Class University (WCU) program of the Ministry of Education, Science and Technology in Korea through KOSEF (R32-10142).}

\begin{abstract}
Author details
${ }^{1}$ Department of Physiology, Faculty of Medicine, University of Toronto, Toronto, Ontario, Canada. 'Department of Brain and Cognitive Sciences, College of Natural Sciences, Seoul National University, Seoul 151-746, Korea. ${ }^{3}$ Department of Bioscience, Faculty of Applied Bioscience, Tokyo University of Agriculture, Tokyo, Japan. ${ }^{4}$ Department of Neuroscience and Oral Physiology, Osaka University Graduate School of Dentistry, Suita, Japan. ${ }^{5}$ Department of Pharmacology, Fourth Military Medical University, Xi'an, China.
\end{abstract}

\section{Authors' contributions}

$H T$ is responsible for performance of electrophysiology and writing the manuscript. MGZ is responsible for performance of electrophysiology. VM, TC and $\mathrm{GD}$ are responsible for performance of biochemical and immunohistochemical studies. SK is responsible for experimental design. MZ is responsible for experimental design and writing the manuscript. All authors read and approved the final manuscript.

\section{Competing interests}

The authors declare that they have no competing interests.

Received: 9 September 2010 Accepted: 16 September 2010 Published: 16 September 2010

\section{References}

1. Tang J, Ko S, Ding HK, Qiu CS, Calejesan AA, Zhuo M: Pavlovian fear memory induced by activation in the anterior cingulate cortex. Mol Pain 2005, 1:6.

2. Wei F, Xu ZC, Qu Z, Milbrandt J, Zhuo M: Role of EGR1 in hippocampal synaptic enhancement induced by tetanic stimulation and amputation. $J$ Cell Biol 2000, 149:1325-1334.

3. Wei F, Zhuo M: Potentiation of sensory responses in the anterior cingulate cortex following digit amputation in the anaesthetised rat. $J$ Physiol 2001, 532:823-833.

4. Zhao MG, Toyoda $H$, Lee $Y S$, Wu LJ, Ko SW, Zhang $X H$, Jia $Y$, Shum $F$, Xu H, Li BM, et al: Roles of NMDA NR2B subtype receptor in prefrontal longterm potentiation and contextual fear memory. Neuron 2005, 47:859-872.

5. Zhuo M: A synaptic model for pain: long-term potentiation in the anterior cingulate cortex. Mol Cells 2007, 23:259-271.

6. Zhuo M: Cortical excitation and chronic pain. Trends Neurosci 2008 31:199-207.

7. Huang YY, Nguyen PV, Abel T, Kandel ER: Long-lasting forms of synaptic potentiation in the mammalian hippocampus. Learn Mem 1996, 3:74-85.

8. Huang YY, Li XC, Kandel ER: CAMP contributes to mossy fiber LTP by initiating both a covalently mediated early phase and macromolecular synthesis-dependent late phase. Cell 1994, 79:69-79.

9. Stanton PK, Sarvey JM: Blockade of long-term potentiation in rat hippocampal CA1 region by inhibitors of protein synthesis. J Neurosci 1984, 4:3080-3088.

10. Calixto E, Thiels E, Klann E, Barrionuevo G: Early maintenance of hippocampal mossy fiber-long-term potentiation depends on protein and RNA synthesis and presynaptic granule cell integrity. J Neurosci 2003, 23:4842-4849.

11. Otani S, Marshall CJ, Tate WP, Goddard GV, Abraham WC: Maintenance of long-term potentiation in rat dentate gyrus requires protein synthesis but not messenger RNA synthesis immediately post-tetanization. Neuroscience 1989, 28:519-526.

12. Mayr B, Montminy M: Transcriptional regulation by the phosphorylationdependent factor CREB. Nat Rev Mol Cell Biol 2001, 2:599-609.

13. Sheng M, Thompson MA, Greenberg ME: CREB: a Ca ${ }^{2+}$-regulated transcription factor phosphorylated by calmodulin-dependent kinases. Science 1991, 252:1427-1430.

14. Lonze BE, Ginty DD: Function and regulation of CREB family transcription factors in the nervous system. Neuron 2002, 35:605-623.

15. Deisseroth $\mathrm{K}$, Mermelstein PG, Xia H, Tsien RW: Signaling from synapse to nucleus: the logic behind the mechanisms. Curr Opin Neurobiol 2003, 13:354-365.

16. West $A E$, Griffith $E C$, Greenberg ME: Regulation of transcription factors by neuronal activity. Nat Rev Neurosci 2002, 3.921-931.

17. Ho N, Liauw JA, Blaeser F, Wei F, Hanissian S, Muglia LM, Wozniak DF, Nardi A, Arvin KL, Holtzman DM, et al: Impaired synaptic plasticity and CAMP response element-binding protein activation in $\mathrm{Ca}^{2+} /$ calmodulindependent protein kinase type IV/Gr-deficient mice. J Neurosci 2000, 20:6459-6472.

18. Kang H, Sun LD, Atkins CM, Soderling TR, Wilson MA, Tonegawa S: An important role of neural activity-dependent CaMKIV signaling in the consolidation of long-term memory. Cell 2001, 106:771-783.

19. Wei F, Qiu CS, Liauw J, Robinson DA, Ho N, Chatila T, Zhuo M: Calcium calmodulin-dependent protein kinase IV is required for fear memory. Nat Neurosci 2002, 5:573-579.

20. Wu LJ, Zhang XH, Fukushima H, Zhang F, Wang H, Toyoda H, Li BM, Kida S, Zhuo M: Genetic enhancement of trace fear memory and cingulate potentiation in mice overexpressing $\mathrm{Ca}^{2+} /$ calmodulin-dependent protein kinase IV. Eur J Neurosci 2008, 27:1923-1932. 
21. Tsvetkov E, Shin RM, Bolshakov VY: Glutamate uptake determines pathway specificity of long-term potentiation in the neural circuitry of fear conditioning. Neuron 2004, 41:139-151.

22. Nguyen PV, Abel T, Kandel ER: Requirement of a critical period of transcription for induction of a late phase of LTP. Science 1994, 265:1104-1107.

23. Barco A, Alarcon JM, Kandel ER: Expression of constitutively active CREB protein facilitates the late phase of long-term potentiation by enhancing synaptic capture. Cell 2002, 108:689-703.

24. Zhang XH, Wu LJ, Gong B, Ren M, Li BM, Zhuo M: Induction- and conditioning-protocol dependent involvement of NR2B-containing NMDA receptors in synaptic potentiation and contextual fear memory in the hippocampal CA1 region of rats. Mol Brain 2008, 1:9.

25. Liauw J, Wu LJ, Zhuo M: Calcium-stimulated adenylyl cyclases required for long-term potentiation in the anterior cingulate cortex. I Neurophysiol 2005, 94:878-882.

26. Zhuo M: Plasticity of NMDA receptor NR2B subunit in memory and chronic pain. Mol Brain 2009, 2:4.

27. Deisseroth $K$, Bito $H$, Tsien RW: Signaling from synapse to nucleus: postsynaptic CREB phosphorylation during multiple forms of hippocampal synaptic plasticity. Neuron 1996, 16:89-101.

28. Deadwyler SA, Dunwiddie T, Lynch G: A critical level of protein synthesis is required for long-term potentiation. Synapse 1987, 1:90-95.

29. Scharf MT, Woo NH, Lattal KM, Young JZ, Nguyen PV, Abel T: Protein synthesis is required for the enhancement of long-term potentiation and long-term memory by spaced training. J Neurophysiol 2002, 87:2770-2777.

30. Barea-Rodriguez EJ, Rivera DT, Jaffe DB, Martinez JL Jr: Protein synthesis inhibition blocks the induction of mossy fiber long-term potentiation in vivo. J Neurosci 2000, 20:8528-8532.

31. Aakalu G, Smith WB, Nguyen N, Jiang C, Schuman EM: Dynamic visualization of local protein synthesis in hippocampal neurons. Neuron 2001, 30:489-502.

32. Steward O, Worley PF: Selective targeting of newly synthesized Arc mRNA to active synapses requires NMDA receptor activation. Neuron 2001, 30:227-240.

33. Osten P, Valsamis L, Harris A, Sacktor TC: Protein synthesis-dependent formation of protein kinase Mzeta in long-term potentiation. J Neurosci 1996, 16:2444-2451.

34. Ouyang Y, Rosenstein A, Kreiman G, Schuman EM, Kennedy MB: Tetanic stimulation leads to increased accumulation of $\mathrm{Ca}(2+) /$ calmodulindependent protein kinase II via dendritic protein synthesis in hippocampal neurons. J Neurosci 1999, 19:7823-7833.

35. Ohmstede $C A$, Jensen $\mathrm{KF}$, Sahyoun NE: $\mathrm{Ca}^{2+} /$ calmodulin-dependent protein kinase enriched in cerebellar granule cells. Identification of a novel neuronal calmodulin-dependent protein kinase. J Biol Chem 1989, 264:5866-5875

36. Melander Gradin H, Marklund U, Larsson N, Chatila TA, Gullberg M: Regulation of microtubule dynamics by $\mathrm{Ca}^{2+} /$ calmodulin-dependent kinase IV/Gr-dependent phosphorylation of oncoprotein 18. Mol Cell Biol 1997, 17:3459-3467.

37. Devinsky O, Morrell MJ, Vogt BA: Contributions of anterior cingulate cortex to behaviour. Brain 1995, 118:279-306.

38. Ko SW, Wu LJ, Shum F, Quan J, Zhuo M: Cingulate NMDA NR2B receptors contribute to morphine-induced analgesic tolerance. Mol Brain 2008, 1:2.

39. Wu LJ, Kim SS, Li X, Zhang F, Zhuo M: Sexual attraction enhances glutamate transmission in mammalian anterior cingulate cortex. Mol Brain 2009, 2:9.

40. Cao XY, Xu H, Wu L, Li XY, Chen T, Zhuo M: Characterization of intrinsic properties of cingulate pyramidal neurons in adult mice after nerve injury. Mol Pain 2009, 5:73.

41. Zhao MG, Toyoda H, Wang YK, Zhuo M: Enhanced synaptic long-term potentiation in the anterior cingulate cortex of adult wild mice as compared with that in laboratory mice. Mol Brain 2009, 2:11.

42. Steenland HW, Wu V, Fukushima H, Kida S, Zhuo M: CaMKIV overexpression boosts cortical $4-7 \mathrm{~Hz}$ oscillations during learning and 1-4 Hz delta oscillations during sleep. Mol Brain 2010, 3:16

43. Frankland PW, Bontempi B, Talton LE, Kaczmarek L, Silva AJ: The involvement of the anterior cingulate cortex in remote contextual fear memory. Science 2004, 304:881-883.
44. Han CJ, O'Tuathaigh CM, van Trigt L, Quinn JJ, Fanselow MS, Mongeau R, Koch C, Anderson DJ: Trace but not delay fear conditioning requires attention and the anterior cingulate cortex. Proc Natl Acad Sci USA 2003, 100:13087-13092.

45. Malenka RC, Bear MF: LTP and LTD: an embarrassment of riches. Neuron 2004, 44:5-21.

46. Kandel ER: The molecular biology of memory storage: a dialogue between genes and synapses. Science 2001, 294:1030-1038.

47. Toyoda H, Zhao MG, Xu H, Wu LJ, Ren M, Zhuo M: Requirement of extracellular signal-regulated kinase/mitogen-activated protein kinase for long-term potentiation in adult mouse anterior cingulate cortex. Mol Pain 2007, 3:36

48. Fukushima H, Maeda R, Suzuki R, Suzuki A, Nomoto M, Toyoda H, Wu LJ, $\mathrm{Xu} \mathrm{H}$, Zhao MG, Ueda K, et al: Upregulation of calcium/calmodulindependent protein kinase IV improves memory formation and rescues memory loss with aging. J Neurosci 2008, 28:9910-9919.

49. Kida S, Josselyn SA, de Ortiz SP, Kogan JH, Chevere I, Masushige S, Silva AJ: CREB required for the stability of new and reactivated fear memories. Nat Neurosci 2002, 5:348-355.

50. Mayford M, Bach ME, Huang YY, Wang L, Hawkins RD, Kandel ER: Control of memory formation through regulated expression of a CaMKII transgene. Science 1996, 274:1678-1683.

51. Wu LJ, Li X, Chen T, Ren M, Zhuo M: Characterization of intracortical synaptic connections in the mouse anterior cingulate cortex using dual patch clamp recording. Mol Brain 2009, 2:32.

52. De March Z, Zuccato C, Giampà C, Patassini S, Bari M, Gasperi V, De Ceballos ML, Bernardi G, Maccarrone M, Cattaneo E, Fusco FR: Cortical expression of brain derived neurotrophic factor and type-1 cannabinoid receptor after striatal excitotoxic lesions. Neuroscience 2008, 152:734-740.

53. Wang H, Gong B, Vadakkan Kl, Toyoda H, Kaang BK, Zhuo M: Genetic evidence for adenylyl cyclase 1 as a target for preventing neurona excitotoxicity mediated by N-methyl-D-aspartate receptors. J Biol Chem 2007, 282:1507-1517.

54. Frey U, Krug M, Reymann KG, Matthies H: Anisomycin, an inhibitor of protein synthesis, blocks late phases of LTP phenomena in the hippocampal CA1 region in vitro. Brain Res 1988, 452:57-65.

55. Nguyen PV, Kandel ER: A macromolecular synthesis-dependent late phase of long-term potentiation requiring CAMP in the medial perforant pathway of rat hippocampal slices. J Neurosci 1996, 16:3189-3198.

56. Huang YY, Kandel ER: Modulation of both the early and the late phase of mossy fiber LTP by the activation of beta-adrenergic receptors. Neuron 1996, 16:611-617.

57. Krug M, Lossner B, Ott T: Anisomycin blocks the late phase of long-term potentiation in the dentate gyrus of freely moving rats. Brain Res Bull 1984, 13:39-42

58. Hu NW, Zhang HM, Hu XD, Li MT, Zhang T, Zhou LJ, Liu XG: Protein synthesis inhibition blocks the late-phase LTP of C-fiber evoked field potentials in rat spinal dorsal horn. J Neurophysiol 2003, 89:2354-2359.

59. Huang $Y Y$, Martin $K C$, Kandel ER: Both protein kinase $A$ and mitogenactivated protein kinase are required in the amygdala for the macromolecular synthesis-dependent late phase of long-term potentiation. J Neurosci 2000, 20:6317-6325.

60. Huang YY, Simpson E, Kellendonk C, Kandel ER: Genetic evidence for the bidirectional modulation of synaptic plasticity in the prefrontal cortex by D1 receptors. Proc Natl Acad Sci USA 2004, 101:3236-3241.

doi:10.1186/1756-6606-3-27

Cite this article as: Toyoda et al.: Calcium/calmodulin-dependent kinase IV contributes to translation-dependent early synaptic potentiation in the anterior cingulate cortex of adult mice. Molecular Brain 2010 3:27. 